\title{
Methodology for reliability assessment of steel wire ropes under fretting fatigue conditions
}

\author{
S. Salleh", M.A. Abdullah², M.F. Abdulhamid ${ }^{2}$ and M.N. Tamin,** \\ ${ }^{1}$ Kiswire R\&D Sdn Bhd, 33 Jalan Senyum, Kampung Wadihana, \\ 80300 Johor Bahru, Johor, Malaysia \\ ${ }^{2}$ Faculty of Mechanical Engineering, Universiti Teknologi Malaysia, \\ 81310 Johor Bahru, Johor, Malaysia \\ *Email: nasirtamin@utm.my \\ Phone: +60127781410; Fax: +6075566159
}

\begin{abstract}
This paper describes a newly-developed damage-based fatigue life model for the longterm reliability assessment of drawn steel wires and wire ropes. The methodology is based on the computed local stress field in the critical trellis contact zone of a stranded wire rope by FE simulations and the estimated fretting damage of the drawn wire material. A case study using a single strand $(1 \times 7)$ steel wire rope with $5.43 \mathrm{~mm}$-dia. drawn wires is employed to demonstrate the damage-based fatigue life prediction procedures. Under applied tensile loading with peak stress corresponding to 50\% MBL $(\triangle P=145 \mathrm{kN}, R=$ 0.1 , the von Mises stress cycles in-phase and with an identical stress ratio to the applied axial load. The damage initiation life at the trellis contact along the core wire is $N_{o}=673$ cycles with an additional 589 load cycles to reach the first separation of the material point. The threshold load cycle for the fretting fatigue damage is predicted to be $12.3 \% \mathrm{MBL}$. An improved data set of the damage model parameters of the drawn steel wires is indispensable in achieving an accurate and validated life prediction model.
\end{abstract}

Keywords: Drawn steel wires; fatigue damage; finite element simulation; reliability assessment; wire ropes.

\section{INTRODUCTION}

Steel wire ropes commonly found in critical applications such as mooring systems for FPSO in the deep sea, bridge tension elements for suspended and stayed structures, and lifting cranes, demand high reliability. In addition, wire ropes are associated with the high cost of installation and are very costly and difficult to replace [1]. These wire ropes are subjected to complex loading systems, including combinations of tension, torsion and bending along with that induced by the self-weight of the component in question. Often, the operating loads are transient or cyclical in nature, occurring over a typical design life of up to 20 years. In offshore applications, wire ropes are also subjected to the corrosive sea environment. The reliability of wire rope is dictated by the failure of a finite number of critical drawn wires through their interaction with neighbouring elements. In addition, the complex interaction of loading types, load ratios and local variables, including contact pressure, friction condition and wear behaviour, require extensive test data on the range of wire rope designs to support the current phenomenological-based reliability prediction approach. Several fatigue life estimation models based on the Weibull statistical 
distribution, modified Wöhler curve and specified endurance function have been reviewed for applications in steel alloys [2,3]. An integrated continuum mechanics model with a genetic algorithm was examined for the multiaxial fatigue response of steel samples [4-7]. Alternately, in this paper, a mechanism-based fatigue life model is proposed for the long-term reliability assessment of wire ropes. Such an approach should encompass both the mechanics of the deformation of wire ropes and the mechanisms of failure of drawn steel wires.

The current design practice for mooring lines accounts for the static offset and resulting tension of the lines. Failures due to the tensile load that exceed the maximum breaking load (MBL) of the wire rope and material fatigue are considered. The mechanics of the wire ropes under tensile loading has been well researched [8]. In the latter, the fatigue design of wire ropes considers both the high-cycle fatigue of the stranded wires and the inherent fretting effects [9-12]. The much-needed fatigue-life data (S-N curves) for the wire ropes are based on data taken from available standards such as DNV OSE301 (DNV, 2004) and the available literature [1, 13-16]. However, the reported fatigue strength of these wire ropes is relatively low at $\left(S_{\text {lim }} / S_{U}\right)=0.15-0.3$ [17]. In addition, most of the available fatigue-life data for the wire ropes are generated from tests at zerodepth (in-air environment). In this respect, extensive axial fatigue-life test data on sheathed steel spiral strands have been established [1]. The work also quantifies the effects of external hydrostatic pressure, representing the deep-water loading condition, on the fatigue performance of the sheathed wire ropes. The load spectral analysis is performed on measured wave data from a given location and environment. The Miner's fatigue life summation rule is used to estimate the fatigue life of the wire ropes [18]. Classical fatigue analysis based on the equivalent nominal stress ranges with the Goodman and/or Gerber approach is employed for interpolation or extrapolation of fatigue behaviour with the axial mean stress effect [13, 14, 19-23]. This classical method is a phenomenological approach based on the mean load over the net section area of the wire rope. Since the fatigue failure of a wire rope is the result of the cumulative failures of the drawn wires in the strands, the failure of individual wires under fatigue stressing and fretting fatigue should be considered. The criterion for fatigue failure of the wire rope is often based on the occurrence of an unacceptable number of wire breaks. In this respect, numerous research works on the fatigue properties of drawn steel wires have been published [24-26]. The mechanism of fretting fatigue in spiral stranded wires has also received much attention [27, 28]. Microstructural changes derived from the drawing operation and their mechanisms in improving the toughness of wires were addressed [29, 30]. The various damage and failure mechanisms of the stranded wires, namely ductile failure, fretting fatigue, wear and corrosion-induced damage have been identified. It was observed that fatigue cracks initiate from the surface non-metallic inclusions, surface oxides or surface defects of the drawn wires [25]. The propagation of such surface cracks was predicted using finite element (FE) simulations [31]. The correlation between the fatigue properties of the wires such as fatigue limit and fatigue threshold, and defect sizes and shapes has already been established $[32,33]$. Such measured data could be utilized to develop a local-approach fatigue life prediction model for wire ropes.

Considering that fatigue crack initiation is a localized material failure event, a damage mechanics-based approach is appropriate to consider while predicting the deformation and fatigue failure processes of the steel wire ropes [34]. Following this approach, the deformation of the drawn steel wires is adequately described using the classical elasto-plasticity constitutive model. In wire rope analysis, the current state of stresses and strains is established using FE simulations for a given wire rope design, 
applying loading and boundary conditions. The geometric model generation of the wire ropes for a given design specification has been described $[8,35]$. Material damage could be quantified using a damage model formulated for the ductile and/or fatigue failure of materials [36-38]. Stress calculations should account for damage-induced elastic modulus degradation due to accumulated fatigue cycles. The calculated region of the separated material points represents the stress-free crack surfaces that propagate with the applied load cycles. This paper discusses damage mechanics-based methodology for the reliability assessment of steel wire ropes under loading conditions such that the fretting fatigue damage mechanism is dominant. The response of the fatigue damage model is quantified for the axial fatigue of a single strand ( $1 \times 7)$ steel wire rope. The characteristic internal fields of stresses and displacements are established using FE simulations of the single strand steel wire rope under tension-tension fatigue loading.

\section{Theoretical Review of Damage Model}

The loss of stiffness and integrity of a material attributed to the presence of microcracks can be quantified by a macroscopic damage parameter, $D$ [34]. Damage of a material refers to the progressive or sudden deterioration of its mechanical strength due to loading, or thermal or chemical effects. Damage can originate from multiple causes, including debonding of atoms, nucleation, or growth and coalescence of microcracks and microcavitities. The history of inelastic deformation may then be defined by the evolution of this internal variable that depends on the expected value of the micro-defect density. Such microcracks and/or microvoids can be modelled by a continuous variable at the microscale, although the damage process is discontinuous in nature [38]. In a onedimensional case, the damage is assumed to be homogeneous and isotropically distributed in the representative volume element (RVE) of the drawn wires in the stranded wire rope. The damage parameter is defined by scaling the damaged area $A_{D}$ by the total cross sectional area $A$ of the RVE such that:

$$
D=\frac{A_{D}}{A}
$$

The damage parameter is continuous and represents the failure of microdefects over the mesoscale volume element. The value of the scalar damage variable $D$ is bounded by $0 \leq D \leq 1$, where $D=0$ represents the undamaged state while rupture (or separation of the material point) occurs at the value of $D=1$. Following damage initiation, the effective stress tensor $\{\tilde{\sigma}\}$ can be represented by:

$$
\{\tilde{\sigma}\}=\frac{\{\sigma\}}{1-D}
$$

where $\{\sigma\}$ is the Cauchy stress tensor.

The prediction of rupture (separation of the material point) requires coupling between plastic flow and damage at the constitutive level. In steel wire rope applications, the dominant damage mechanisms are ductile failure, fretting fatigue, fretting wear and corrosion fatigue. This paper discusses the methodology for damage and failure assessment of wire rope materials under high-cycle fretting fatigue conditions. 


\section{High-Cycle Fatigue Damage Model}

In high-cycle fatigue where the amplitude of the loading is low, the amplitude of the plastic strain is relatively small or negligible at the mesoscale when compared to the elastic strain amplitude. Drawn steel wires are assumed to behave in a quasi-brittle manner at the mesoscale, with localized damage growth occurring at the microscale. Thus, the material is modelled as a damageable microinclusion embedded in an elastic mesoelement, as illustrated in Figure 1. While the mesoscale matrix is elastic, the microscale inclusion experiences elastic, plastic and damage. In addition, it is assumed that the inclusion is subjected to the same strain state (or strain rate) as the mesoscale matrix.

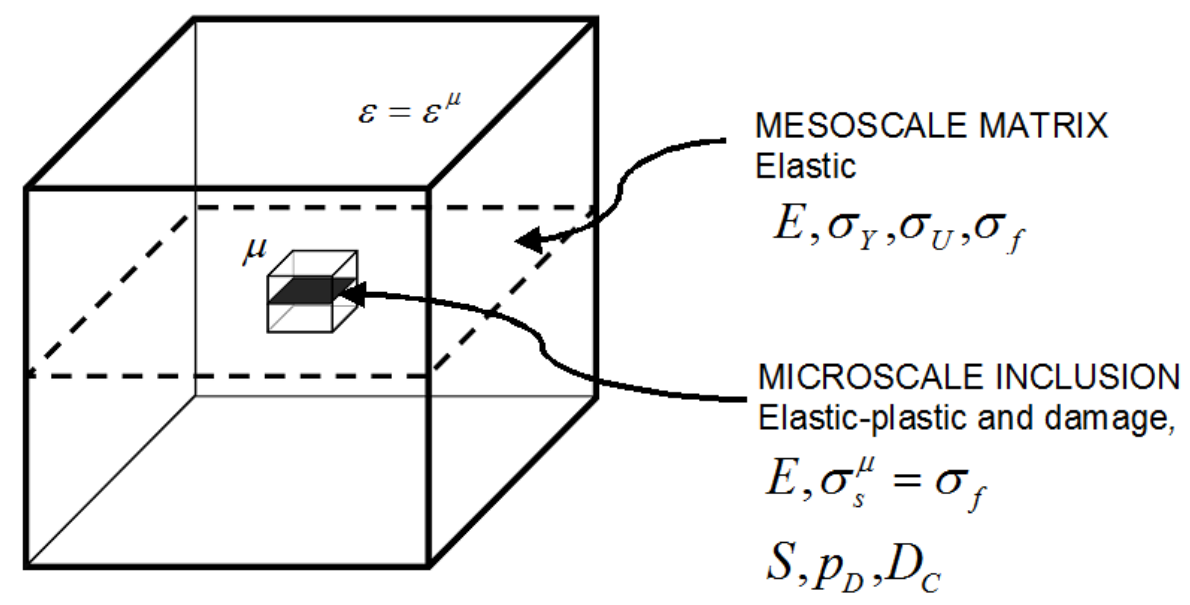

Figure 1. Representative volume element (RVE) for the two-scale model (adapted from [38]).

Based on the kinetic damage law for the inclusion, and considering the relatively large plastic strain compared to the elastic component of a microvolume $\mu$, the evolution of damage is expressed as [39]:

$$
\dot{D}=\frac{Y^{\mu}}{S} \dot{p}^{\mu}
$$

The superscript $\mu$ refers to quantities for the microelement and $S$ is a material damage parameter. It is desirable to express the damage strain energy release rate $Y^{\mu}$ and the accumulated plastic strain rate $\dot{p}^{\mu}$ as functions of the macroscopic quantities such as strain $\varepsilon$ and stress $\sigma$. The plastic strain rate $\dot{p}^{\mu}$ of the elastic-perfectly plastic microvolume is equal to the equivalent strain rate of the elastic mesoscale matrix, i.e. $\dot{p}^{\mu}=\sqrt{\frac{2}{3} \dot{\varepsilon}_{i j}^{p} \dot{\varepsilon}_{i j}^{p}}=\sqrt{\frac{2}{3} \dot{\varepsilon}_{i j}^{D} \dot{\varepsilon}_{i j}^{D}}=\dot{\varepsilon}_{e q}$. The effect of stress triaxiality on the evolution of damage is expressed through a factor function of the hydrostatic-to-equivalent stress $\left(\frac{\sigma_{H}^{\mu}}{\sigma_{e q}^{\mu}}\right)$ in defining the damage strain energy release rate $Y^{\mu}$ as [39]: 


$$
Y^{\mu}=\frac{\sigma_{e q}^{\mu 2}}{2 E(1-D)^{2}}\left[\frac{2}{3}(1+v)+3(1-2 v)\left(\frac{\sigma_{H}^{\mu}}{\sigma_{e q}^{\mu}}\right)^{2}\right]
$$

The elastic properties $E$ and $v$ are the elastic modulus and Poisson's ratio of the material, respectively. Since the damaged inclusion is assumed to be perfectly plastic, we have $\sigma_{e q}^{\mu}=(1-D) \sigma_{s}^{\mu}$, where $\sigma_{s}^{\mu}$ is the plastic threshold limit. Considering pure elasticity at the mesoscale leads to $\sigma_{H}^{\mu}=(1-D) \sigma_{H}$, the hydrostatic stress. It is further approximated that $\dot{D}=0$ if $\sigma_{e q}<\sigma_{f}$, the fatigue limit of the material. Thus, Eq. (3) can be written as:

$$
\dot{D}=\frac{\sigma_{s}^{\mu 2}}{2 E S}\left[\frac{2}{3}(1+v)+3(1-2 v)\left(\frac{\sigma_{H}}{\sigma_{s}^{\mu}}\right)^{2}\right] \dot{\varepsilon}_{e q} \text { if }\left\{\begin{array}{l}
\varepsilon_{e q} \geq p_{D} \\
\sigma_{e q}>\sigma_{f}
\end{array}\right.
$$

where $p_{D}$ is the damage strain threshold. It is noted that a one-dimension (1-D) stress state at the mesoscale accounts for a 3-D stress state at the microscale due to the mismatch of Poisson's ratio and the plastic contraction coefficient at the microscale. Thus, for 1-D at the mesoscale, the damage equivalent effective stress term assumes the value of the plastic threshold limit $\sigma_{s}^{\mu}$ is taken to be equal to the fatigue limit of the material, $\sigma_{f}$ thus:

$$
\frac{\sigma_{H}}{\sigma_{f}}=\frac{\sigma}{3 \sigma_{f}} \quad \text { and } \quad \dot{\varepsilon}_{e q}=|\dot{\varepsilon}|=\frac{|\dot{\sigma}|}{E}
$$

Equation (5) can then be written as:

$$
\dot{D}=\frac{\sigma_{f}^{2}}{2 E^{2} S}\left[\frac{2}{3}(1+v)+\frac{1}{3}(1-2 v)\left(\frac{\sigma}{\sigma_{f}}\right)^{2}\right]|\dot{\sigma}| \text { if }\left\{\begin{array}{l}
\varepsilon_{e q} \geq p_{D} \\
\sigma_{e q}>\sigma_{f}
\end{array}\right.
$$

The influence of mean stress is such that the stress amplitude that induces a certain number of cycles to failure decreases as the mean stress increases. In addition, the damage rate concerns only positive stress and an integration over one cycle gives the damage per cycle as:

$$
\begin{aligned}
\frac{\delta D}{\delta N} & =\frac{\sigma_{f}^{2}}{2 E^{2} S} \int_{\sigma_{f}}^{\sigma_{M}}\left[\frac{2}{3}(1+v)+\frac{1}{3}(1-2 v)\left(\frac{\sigma}{\sigma_{f}}\right)^{2}\right] d \sigma \\
& =\frac{2 \sigma_{f}^{2}}{E^{2} S}\left[\frac{2}{3}(1+v)\left(\sigma_{M}-\sigma_{f}\right)+\frac{1-2 v}{9 \sigma_{f}^{2}}\left(\sigma_{M}^{3}-\sigma_{f}^{3}\right)\right]
\end{aligned}
$$

where $\sigma_{M}$ denotes the maximum stress in the cycle. The evolution of the damage for the initial conditions $\left(N=N_{o} ; D=0\right)$ is obtained as:

$$
D=\frac{2 \sigma_{f}^{2}}{E^{2} S}\left[\frac{2}{3}(1+v)\left(\sigma_{M}-\sigma_{f}\right)+\frac{1-2 v}{9 \sigma_{f}^{2}}\left(\sigma_{M}^{3}-\sigma_{f}^{3}\right)\right]\left(N-N_{o}\right)
$$


It is worth noting that Young's modulus of the material $E$ shall degrade with accumulated load cycles. The number of cycles $N_{o}$ needed for $\varepsilon_{e q}$ to reach the damage threshold $p_{D}$ is given by:

$$
N_{o}=\frac{p_{D}}{2 \Delta \varepsilon}=\frac{E p_{D}}{2 \Delta \sigma}=\frac{E p_{D}}{4\left(\sigma_{M}-\bar{\sigma}\right)}
$$

with the damage strain threshold, $p_{D}=\frac{\sigma_{u}-\sigma_{f}}{\sigma_{f}-\frac{\sigma_{f}^{2}}{\sigma_{Y}}}, \sigma_{Y}$ is the yield stress of the material and $\bar{\sigma}$ is the cyclic mean stress.

The number of cycles to rupture for the material point $N_{R}$ is reached when the damage variable reaches a critical level, $D=D_{C}$ :

$$
N_{R}=N_{o}+\frac{D_{C}}{\frac{2 \sigma_{f}^{2}}{E^{2} S}\left[\frac{2}{3}(1+v)\left(\sigma_{M}-\sigma_{f}\right)+\frac{1-2 v}{9 \sigma_{f}^{2}}\left(\sigma_{M}^{3}-\sigma_{f}^{3}\right)\right]}
$$

The evolution of damage can also be expressed in a simpler way:

$$
D=D_{C} \frac{N-N_{o}}{N_{R}-N_{o}}
$$

\section{METHODS AND MATERIALS}

\section{Drawn Wire Material and Experimental Procedure}

The steel wire rope considered in the case study is a single strand $(1 \times 7)$ wire rope construction. The geometry of the wire rope is illustrated in Figure 2, along with the design parameters. The core wire is straight. The chemical composition of the drawn wires is (in wt.\%) $0.83 \mathrm{C}, 0.91 \mathrm{Si}, 0.717 \mathrm{Mn}, 0.0124 \mathrm{P}, 0.0031 \mathrm{~S}$, and $0.015 \mathrm{Cu}$, with the remaining being $\mathrm{Fe}$. The preferred orientation of the grains along the drawing direction is prominent. Such microstructure results in the wires having superior strength in the axial direction.

The resulting true stress-plastic strain curve of the drawn steel wire is shown in Figure 3(a). The modulus of elasticity is determined at $202 \mathrm{GPa}$ and the initial yield strength is $1.690 \mathrm{GPa}$. The true fracture strength is $\sigma_{R}=2.164 \mathrm{GPa}$, with the corresponding true plastic strain at fracture $\varepsilon_{R}=6.78 \%$. Although brittle-like behaviour associated with extensive hardening of the drawn wire is apparent on the fracture surface, the ductile fracture feature as signified by dimples is displayed at the microscopic level, as shown in the fractograph in Figure 3(b). Limited necking of the tensile wire specimen at fracture is also observed. The drawn steel wires behave as a quasi-brittle material, which thus renders the fatigue damage model as described above appropriate for predicting the fretting fatigue behaviour of the steel wire rope. 

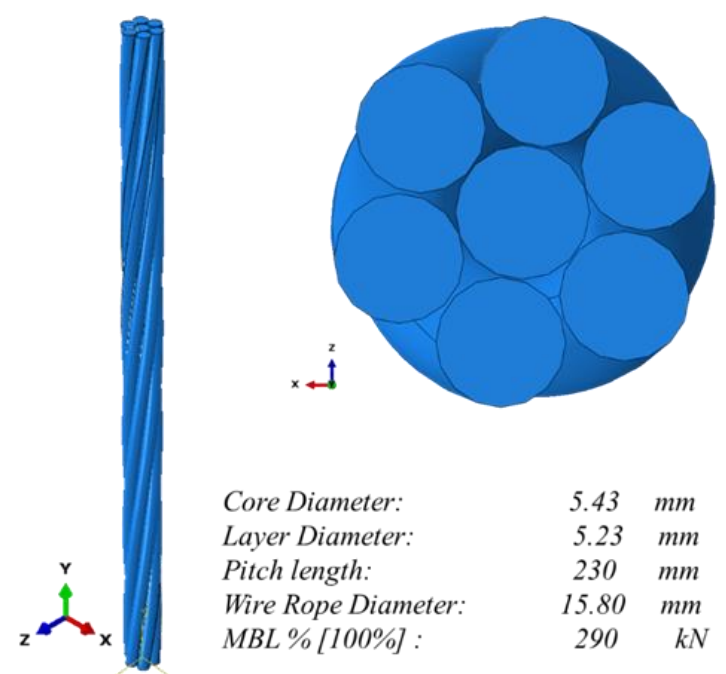

$\begin{array}{lcc}\text { Core Diameter: } & 5.43 & \mathrm{~mm} \\ \text { Layer Diameter: } & 5.23 & \mathrm{~mm} \\ \text { Pitch length: } & 230 & \mathrm{~mm} \\ \text { Wire Rope Diameter: } & 15.80 & \mathrm{~mm} \\ \text { MBL\%[100\%] : } & 290 & \mathrm{kN}\end{array}$

Figure 2. Geometry and geometrical properties of a $(1 \times 7)$ wire rope.

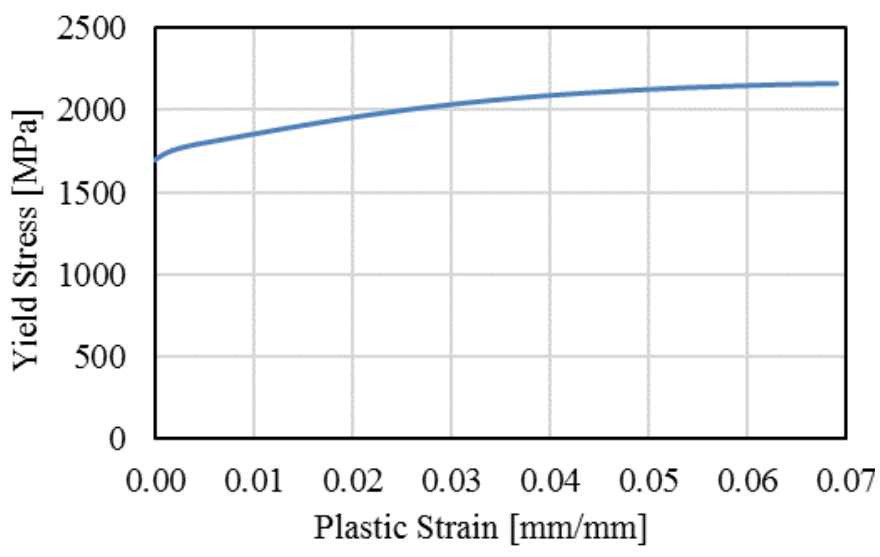

(a)

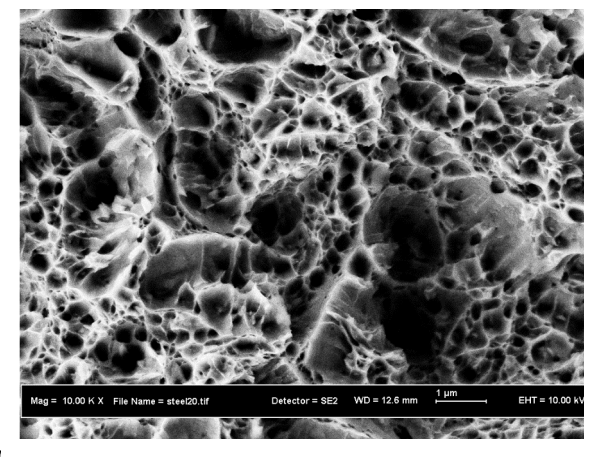

(b)

Figure 3. (a) True stress-plastic strain curve and (b) microscopic ductile fracture feature of drawn steel wire.

Fatigue life tests were performed on the drawn steel wires at the load ratio of minimum-to-maximum load $R=0.1$ and loading frequency of $30 \mathrm{~Hz}$. The gage length of the specimen is $100 \mathrm{~mm}$. The drawn wires are tested in the as-received condition. The resulting fatigue strength-life (S-N) curve is shown in Figure 4 (circle symbols). The solid line representing the published fatigue life of $0.9 \mathrm{~mm}$ eutectoid steel wires is superimposed onto the plot for comparative purposes. The effect of size (wire diameter) on fatigue life is consistent; a larger diameter results in a relatively shorter fatigue life for the wires. This is postulated by the greater number of manufacturing defects or microcracks inherent in a larger volume of the material within the gage section. The fatigue strength of the drawn steel wires is determined at $305 \mathrm{MPa}\left(N=3.5 \times 10^{5}\right.$ cycles, $R=0.1$ ). 


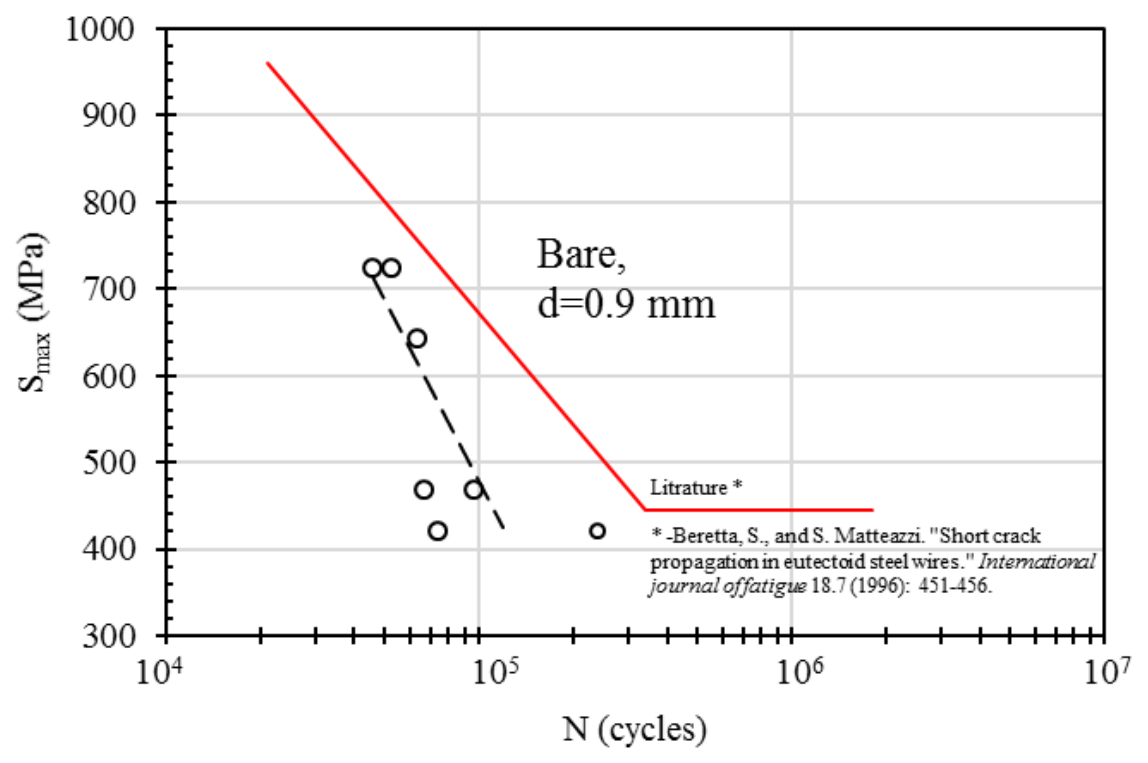

Figure 4. Fatigue strength-life $(\mathrm{S}-\mathrm{N})$ curve of the drawn steel wires, $R=0.1$.

\section{Finite Element Simulation}

Finite element (FE) simulations of the single strand $(1 \times 7)$ wire rope were performed for the axial fatigue loading to establish the internal stress fields. A total length of $330 \mathrm{~mm}$ of the wire rope is modelled (Figure 2). This should account for a full pitch length of 230 $\mathrm{mm}$ in the central length region, while the remaining lengths at both end regions are used to apply the loading and boundary conditions. One end of the wire rope is fixed in both translational $\left(U_{x}=U_{y}=U_{z}=0\right)$ and rotational $\left(U R_{x}=U R_{y}=U R_{z}=0\right)$ displacements, while the other free end is subjected to an applied axial load, but without rotation $\left(U R_{y}=0\right)$. An axial fatigue load consisting of the load amplitude $\Delta P=145 \mathrm{kN}$ and load ratio $R=0.1$ is applied. The maximum load magnitude is $50 \%$ of the maximum breaking load (i.e. $50 \% \mathrm{MBL}$ ) of the wire rope. The contact condition of the wires is prescribed to follow Coulomb's law with an assumed coefficient of friction $\operatorname{cof}=0.5$, considering the surface roughness of the drawn wires. Based on the outcome of the mesh convergence study, the single strand $(1 \times 7)$ wire rope geometry is discretized into 203208 continuum 8-node elements.

\section{RESULTS AND DISCUSSION}

\section{Distribution of the Maximum Principal Stress}

A typical distribution of the maximum principal stress in the wire rope material corresponding to the peak applied load cycle is shown in Figure 5(a). The computed highest magnitude of $1.27 \mathrm{GPa}$ at the localized end region of the wire rope model is due to the applied boundary conditions, and thus should not be considered in the fatigue analysis. In this single strand wire rope under tension-tension loading cycles, the core wire is the most critically stressed as it has the shortest length within the pitch distance of the wire rope. With the prescribed iso-strain end condition, the core wire experiences the greatest displacement. Each material point in each drawn wire of the wire rope experiences a different stress amplitude but at the same stress ratio of $R=0.1$. In addition, the surrounding wires stretch around, inducing the contact pressure at selected locations during the tensile stressing. The highest magnitude of the maximum principal stress, 
occurring in the trellis contact region of the core wire, however, is about $83 \%$ of the yield strength level of the drawn wires at $1.690 \mathrm{GPa}$, as shown in Figure 5(b). Thus, high cycle fatigue analysis is appropriate. It is also noted that the maximum principal stress magnitude is comparable to the equivalent (von Mises) stress.

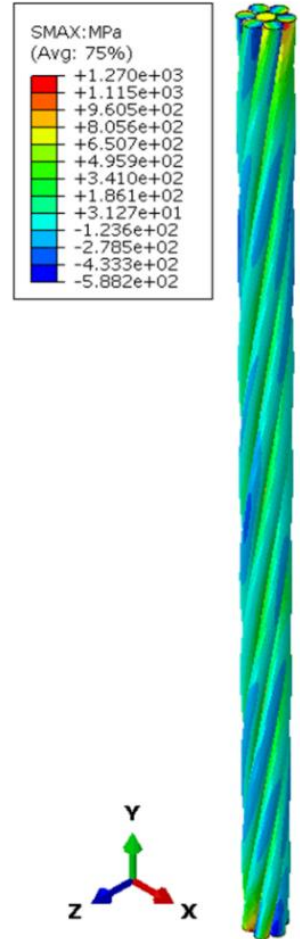

(a)
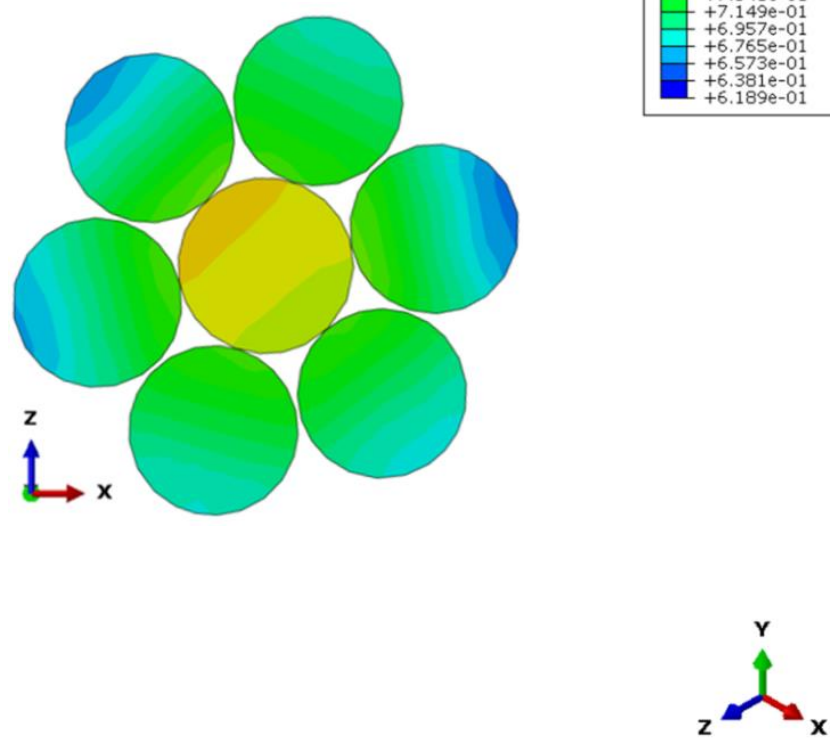

(b)

Figure 5. Maximum principal stress distribution (a) in the wire rope and across the critical section with the highest contact pressure; (b) Similar normalized distribution in the core wire.

\section{Evolution of Internal Variables}

The evolution of internal variables, namely the displacement, von Mises stress and contact pressure at the selected critical location (trellis contact region) in the wire rope model is compared in Figure 6. The displacement of the free end of the model and the von Mises stress in the element near the contact region of the wires evolves in-phase with the applied sinusoidal axial load. A strain rate-dependent effect is not considered in view of the low frequency loading. The peak von Mises stress in the trellis region is $1.240 \mathrm{GPa}$ with the stress range of $1.116 \mathrm{GPa}$. The characteristic evolution and distribution of the contact pressure is presented in Figure 6 (lower left plot) and Figure 7, respectively. In the as-received configuration (see Figure 2) there exists spacing between the wires in the stranded wire rope. As the wire rope is being stretched, the core wire experiences a direct axial deformation while the other wires begin to straighten and fill-up the available gaps. The contact pressure correspondingly increases initially. The observed kink in the contact pressure evolution curve at $140 \mathrm{MPa}$ is associated with the set-in condition of the drawn wires in the wire rope. The subsequent evolution characteristic of the contact pressure follows the sinusoidal load input. A similar kink is observed on the curve in the elastic unloading part of the load cycle. 

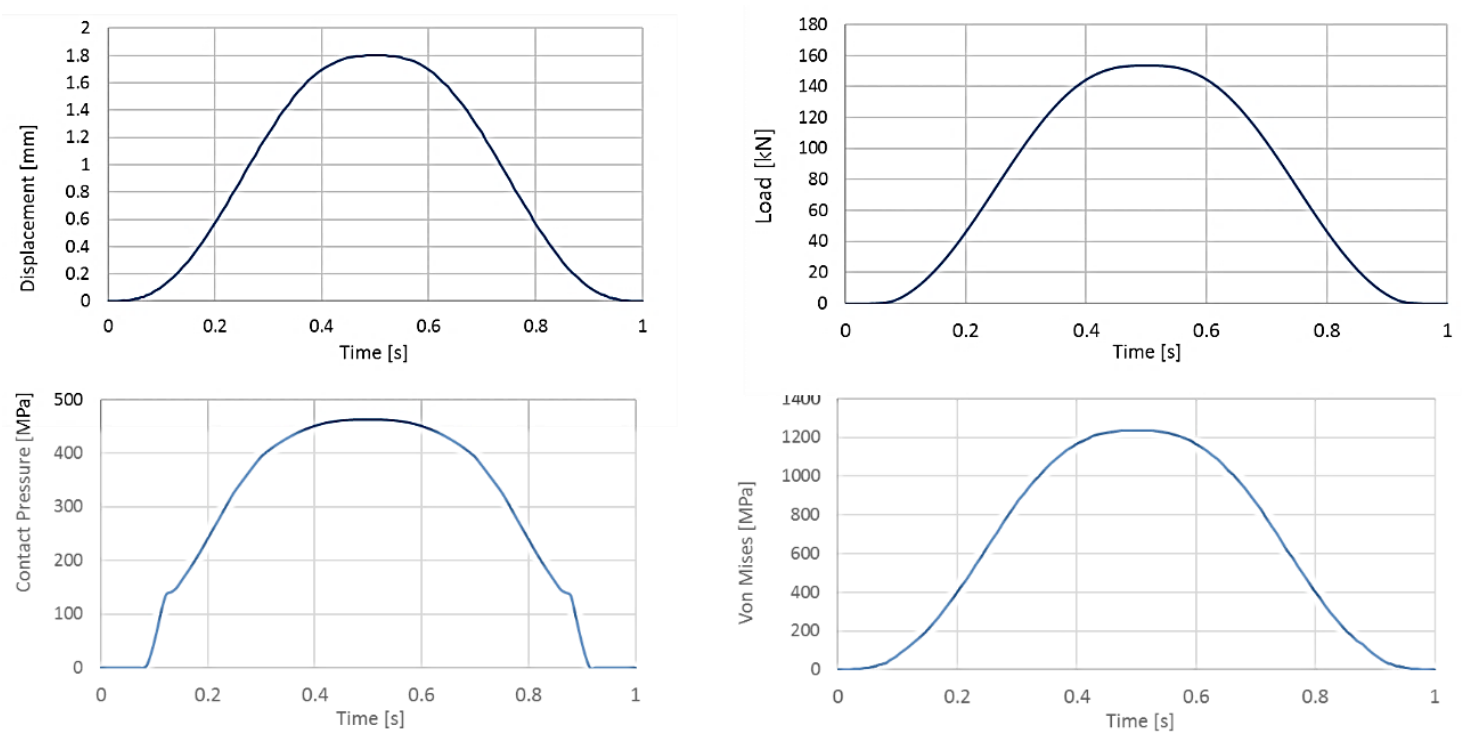

Figure 6. Evolution of free end displacement, and von Mises stress and contact pressure in the trellis contact region during a typical applied sinusoidal load cycle.
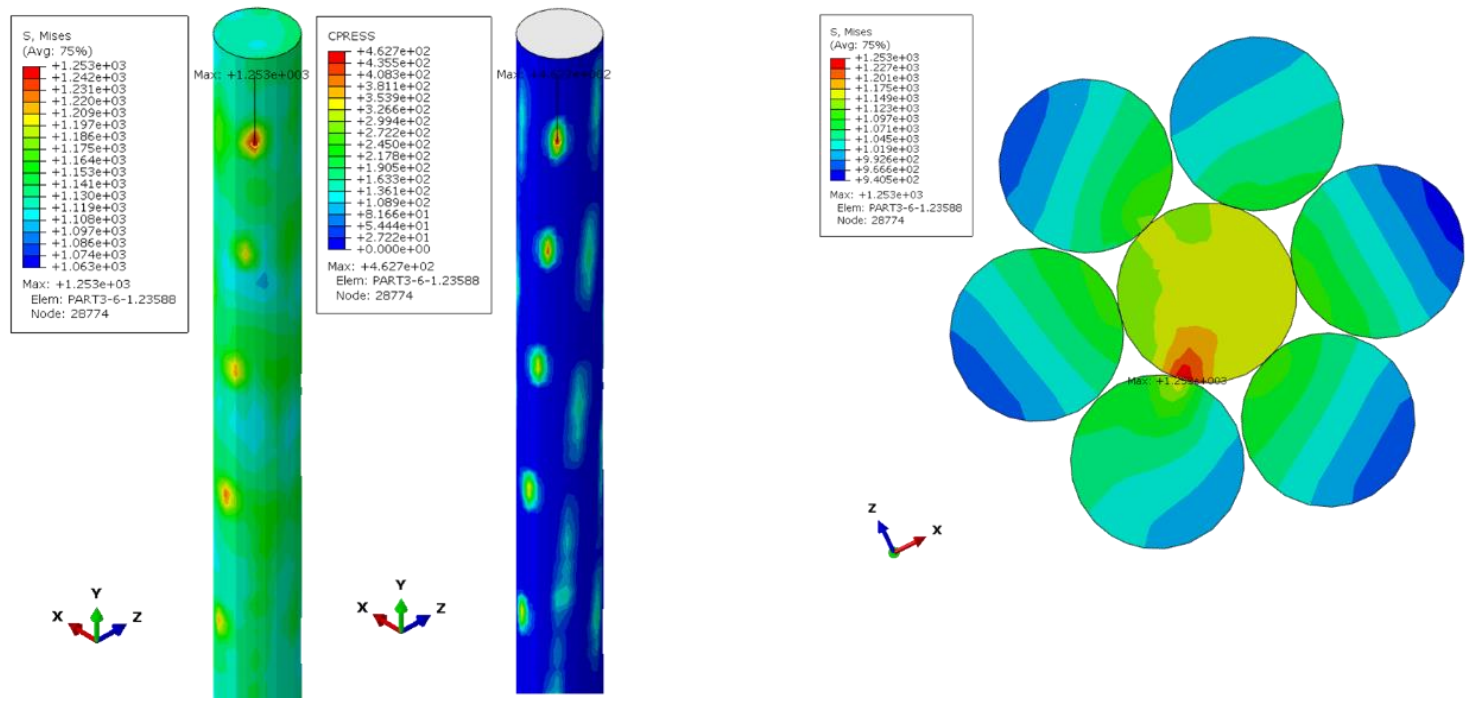

Figure 7. Distribution of contact pressure (CPRESS) and von Mises stress along the core wire of the single strand $(1 \times 7)$ wire rope.

\section{Fretting Fatigue Damage}

The regular spacing of the trellis contact locations along the core wire is dependent on the wire rope design parameters (lay angle) as illustrated in Figure 7. The small relative displacement across the contact area with such high contact pressure causes the fretting fatigue of the wires. A small lay angle will result in a line "long" contact between the layer and core wires that subsequently causes fretting wear failure of the wire rope. The fretting fatigue damage is localized in the trellis contact region where the induced contact pressure of the stranded wires is significant. The variation of the calculated number of cycles for the damage initiation $N_{o}$ with the stress amplitude, based on Eq. (10), is shown in Figure 8. Equation (10) shows the damage initiation life to be independent of the mean stress. The calculated damage initiation life in the case study considered is $N_{o}=673$ 
cycles, corresponding to $\Delta \sigma=1116 \mathrm{MPa}$ (maximum stress is $50 \% \mathrm{MBL}$ of the steel wire rope). The initiation life is prolonged at lower stress ranges. Since the fatigue damage of the microinclusion is considered to initiate for the stress level above the fatigue limit of the mesoscale material $\sigma_{f}=305 \mathrm{MPa}$, the threshold stress range for the damage initiation is calculated at $\Delta \sigma_{t h}=274.5 \mathrm{MPa}$. This corresponds to $12.3 \% \mathrm{MBL}$ of the wire rope. At this applied load amplitude (with $R=0.1$ ), the damage initiation life is predicted at $N_{o}=$ 2737 cycles, as indicated in the figure. The material properties and damage model parameters used in the calculations are summarized in Table 1.

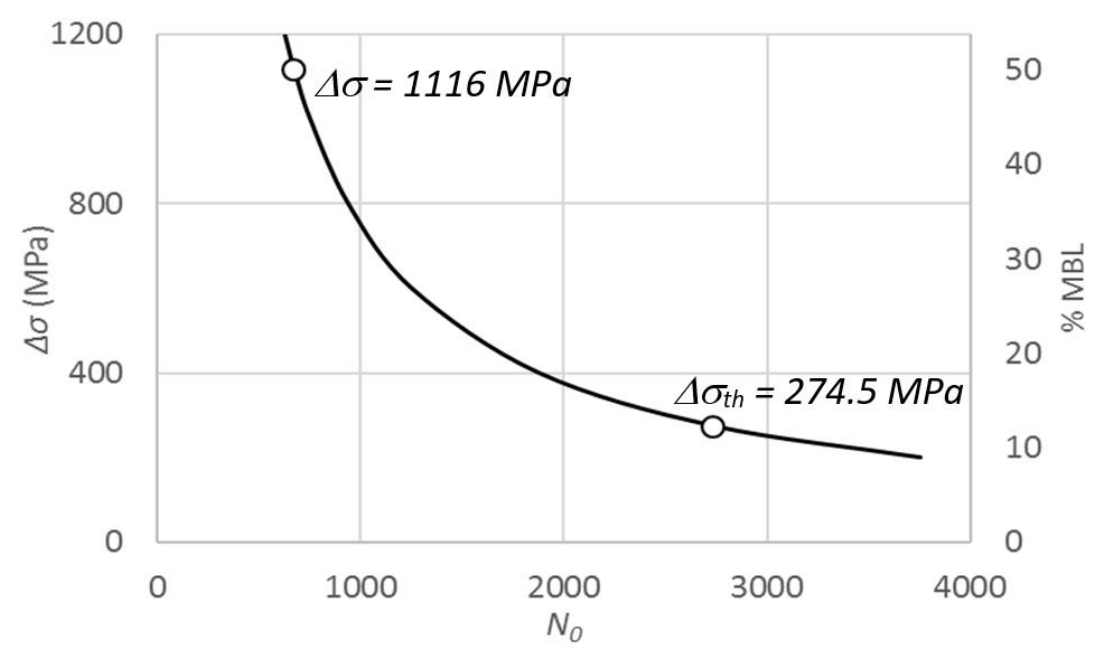

Figure 8. A variation of the damage initiation life $N_{o}$ (cycles) with the stress range.

Table 1. Damage model parameters for the drawn steel wires.

\begin{tabular}{llc}
\hline Parameter & Symbol & Value \\
\hline Elastic modulus & $E(\mathrm{GPa})$ & 202 \\
Yield strength & $\sigma_{Y}(\mathrm{MPa})$ & 1690 \\
Tensile strength & $\sigma_{u}(\mathrm{MPa})$ & 2164 \\
Poisson's ratio & $v$ & 0.28 \\
Fatigue limit & $\sigma_{f}(\mathrm{MPa})$ & 305 \\
Damage parameter & $S(\mathrm{MPa})$ & 6 \\
Critical damage & $D_{C}$ & 0.8 \\
\hline
\end{tabular}

Once damage has initiated at the critical material point in the core wire, the evolution of the damage for the continuing load cycles is calculated according to Eq. (9). The fatigue damage evolution characteristic for two different localized stress ranges is compared in Figure 9. The critical damage parameter value is taken as $D_{C}=0.80$ based on limited experimental data [39]. The calculated number of cycles to rupture or separation of the material point for the case study is $N_{R}=1262$ cycles. This corresponds to the fatigue crack initiation life of the core wire in the single strand (1x7) wire rope at the applied load range $\Delta P=145 \mathrm{kN}, R=0.1$ (50\%MBL). Damage evolves at a much slower rate for the threshold stress range to damage initiation $\left(\Delta \sigma_{t h}=274.5 \mathrm{MPa}\right)$ as indicated in the lower slope of the line. 


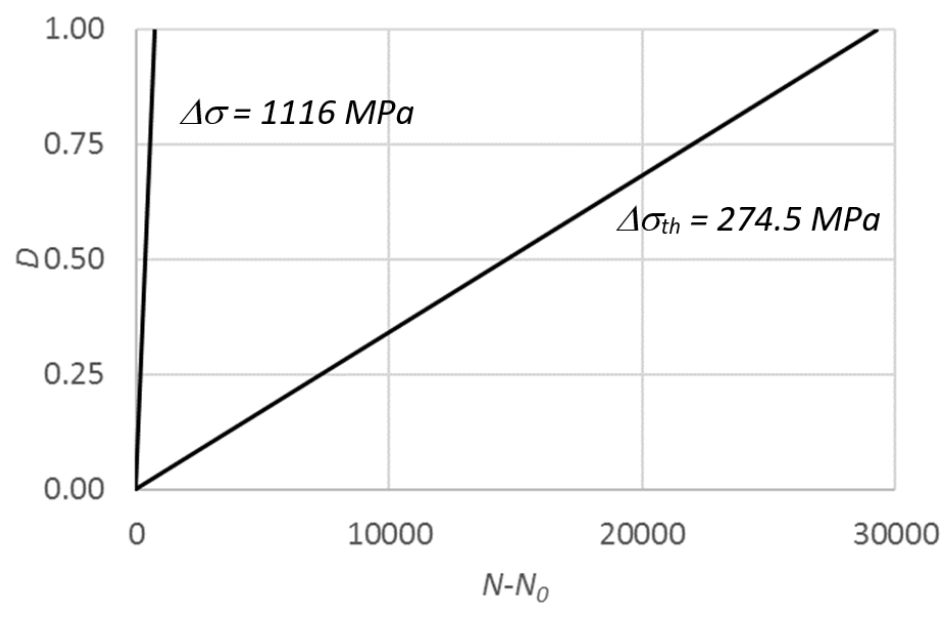

Figure 9. Fatigue damage evolution rates at different stress ranges $(R=0.1)$.
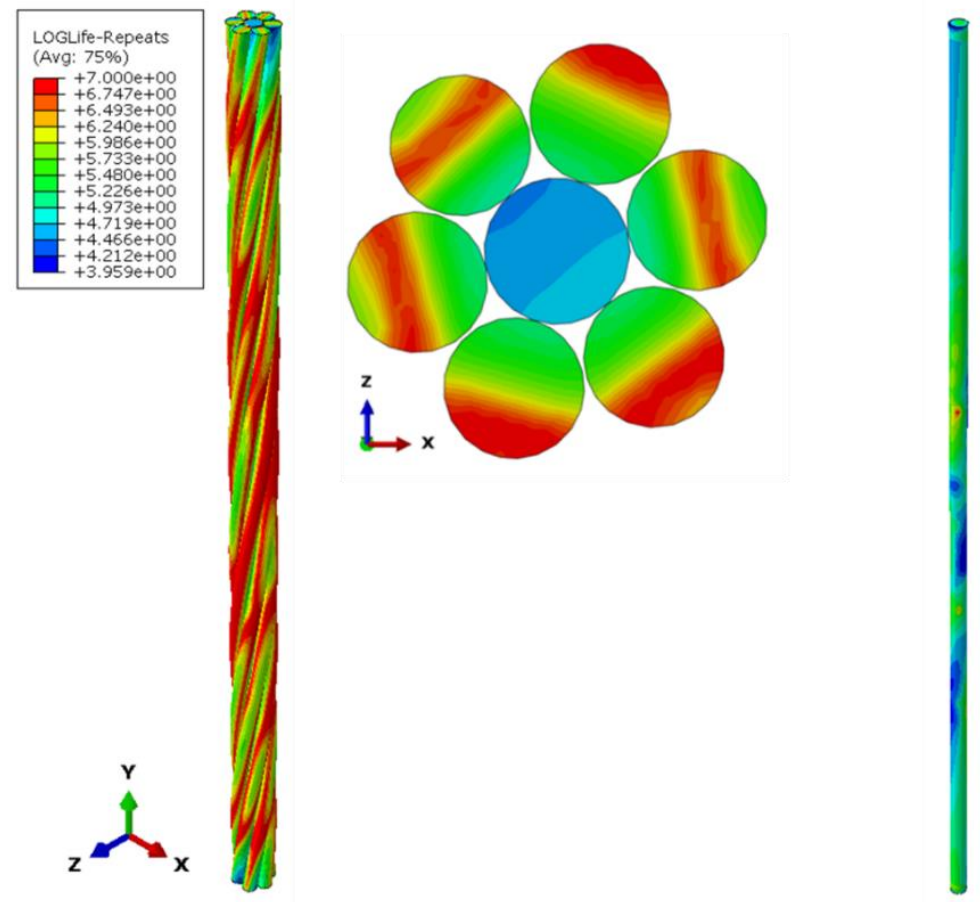

Figure 10. Fatigue log-life plot for the wire rope subjected to $\Delta P=145 \mathrm{kN}, R=0.1$. The log-life contour of the cross section corresponds to the critical plane. The core wire log-life plot is shown on the right.

The calculations, thus far, have been performed to identify the first critical material point in the core wire to experience the onset of damage and the subsequent damage evolution to rupture. Once the "microcrack" has initiated, the load initially carried by the core wire is shed to the neighbouring wires. This results in material damage acceleration, particularly for the material elements in the vicinity of the microcrack. The additional load cycles propagate the region of damaged and separated material points across the section of the core wire. A region with the collection of separated material points could be viewed as a traction-free structural fatigue crack. The reliability of the wire rope should be established based on the accumulated damaged volume within a pitch 
length. In a wire rope construction containing multiple strands of drawn wires, the fatigue life of the wire rope is dictated by the allowable maximum number of fractured wires.

Prediction of the fatigue life of the wire rope based on the classical high-cycle fatigue analysis is performed for comparative purpose. Identical geometry (Figure 2), loading conditions $(\Delta P=145 \mathrm{kN}, R=0.1)$ and S-N curve (Figure 4) to the case study are employed. Recall that the S-N curve represents the fatigue life of the drawn steel wire specimen for each applied maximum stress level $(R=0.1)$, assuming that the fatigue crack propagation stage to fracture is relatively short compared to the crack initiation life. The resulting FE-calculated elastic stresses is reproduced (Figure 5 to 7). The nonuniform stress field in the drawn wires of the wire rope results in the log-life contour plot as shown in Figure 10. The fatigue life of the critical core wire is conservatively interpreted based on the shortest life of $N_{f}=10^{4.2}$ cycles (or 15850 cycles) for the material point in the vicinity of the trellis contact region where the highest contact pressure acts. The analysis does not identify neither the fatigue crack initiation life, nor the crack propagation behaviour of the drawn wire. The fracture process of subsequent wires could not be adequately quantified.

\section{CONCLUSIONS}

A life prediction methodology for steel wire ropes under fretting fatigue loading conditions has been proposed. The approach employs the cyclic damage-based model accounting for the mean stress effect. The response of the model is examined using the FE simulation of a single strand $(1 \times 7)$ steel wire rope subjected to cyclic axial load $(\Delta P$ $=145 \mathrm{kN}, R=0.1)$. The results show that:

- The von Mises stress cycles in-phase and with an identical stress ratio as the applied axial load.

- The peak of the threshold stress range corresponds to $12.3 \% \mathrm{MBL}$ of the wire rope.

- The critical material point at the trellis contact in the core wire experiences the first damage initiation event and separation at 673 and 1262 cycles, respectively.

\section{ACKNOWLEDGMENTS}

This research is supported by Kiswire R\&D Sdn. Bhd., Johor Bahru, Malaysia and Universiti Teknologi Malaysia through the Kiswire-UTM Contract Research Grant No. 4C043 and UTM Matching Grant No. 00M49, respectively.

\section{REFERENCES}

[1] Raoof M, Davies TJ. Axial fatigue design of sheathed spiral strands in deep water applications. International Journal of Fatigue. 2008;30:2220-38.

[2] Mahmud M, Abdullah S, Yunoh M, Ariffin A, Nopiah Z. Damaging fatigue cycles determination for random service loadings using mixed Weibull analysis. International Journal of Automotive and Mechanical Engineering. 2016;13.

[3] Kamal M, Rahman MM. Fatigue life estimation models: a state of the art. International Journal of Automotive and Mechanical Engineering. 2014;9:1599.

[4] Mahmud M, Abdullah S, Yunoh MFM, Ariffin AK, Nopiah ZM. Damaging fatigue cycles determination for random service loadings using mixed Weibull 
analysis. International Journal of Automotive and Mechanical Engineering. 2016;13:3628-41.

[5] Mohamed SAN, Abdullah S, Arifin A, Ariffin AK, Padzi MM. Characterization of the biaxial fatigue behaviour on medium carbon steel using the strain-life approach. International Journal of Automotive and Mechanical Engineering. 2016;13:3262-77.

[6] Kamal M, Rahman MM. Finite element-based fatigue behaviour of springs in automobile suspension. International Journal of Automotive and Mechanical Engineering. 2014;10:1910-9.

[7] Kamal M, Rahman MM, Sani MSM. Application of multibody simulation for fatigue life estimation. International Journal of Automotive and Mechanical Engineering. 2013;7:912-23.

[8] Prawoto Y, Mazlan RB. Wire ropes: Computational, mechanical, and metallurgical properties under tension loading. Computational Materials Science. 2012;56:174-8.

[9] Winkler J, Georgakis CT, Fischer G. Fretting fatigue behavior of high-strength steel monostrands under bending load. International Journal of Fatigue. 2015;70:13-23.

[10] Wang D, Zhang D, Wang S, Ge S. Finite element analysis of hoisting rope and fretting wear evolution and fatigue life estimation of steel wires. Engineering Failure Analysis. 2013;27:173-93.

[11] Cruzado A, Urchegui M, Gómez X. Finite element modeling and experimental validation of fretting wear scars in thin steel wires. Wear. 2012;289:26-38.

[12] Sasaki K, Iwakura S, Takahashi T, Moriya T, Furukawa I. Estimating the fatigue life of wire rope with a stochastic approach. Journal of Solid Mechanics and Materials Engineering. 2007;1:1052-62.

[13] Alani M, Raoof M. Effect of mean axial load on axial fatigue life of spiral strands. International Journal of Fatigue. 1997;19:1-11.

[14] Birkenmaier M. Fatigue resistant tendons for cable-stayed construction. International Association for Bridge and Structural Engineering; 1980.

[15] Suh J-I, Chang SP. Experimental study on fatigue behaviour of wire ropes. International Journal of Fatigue. 2000;22:339-47.

[16] Kamal M, Rahman MM, Rahman AGA. Fatigue life evaluation of suspension knuckle using multibody simulation technique. Journal of Mechanical Engineering and Sciences. 2012;3:291-300.

[17] Kao P-W, Byrne J. Fatigue initiation study of TMT eutectoid steel. Metallurgical and Materials Transactions A. 1982;13:855-64.

[18] Han JS, Kim YH, Son YJ, Choi HS. A comparative study on the fatigue life of mooring systems with different composition. Journal of Hydrodynamics, Ser B. 2010;22:452-6.

[19] Hobbs R, Ghavani K. The fatigue of structural wire strands. International Journal of Fatigue. 1982;4:69-72.

[20] Sivananth V, Vijayarangan S. Fatigue life analysis and optimization of a passenger car steering knuckle under operating conditions. International Journal of Automotive and Mechanical Engineering. 2015;11:2417-29.

[21] Kamal M, Rahman MM. An Integrated approach for fatigue life estimation based on continuum mechanics theory and genetic algorithm. International Journal of Automotive and Mechanical Engineering. 2015;11:2756-70. 
[22] Kamal M, Rahman MM. Fatigue life estimation based on continuum mechanics theory with application of genetic algorithm. International Journal of Automotive and Mechanical Engineering. 2015;11:2686-98.

[23] Kamal M, Rahman MM. Dual-criteria method for determining critical plane orientation for multiaxial fatigue prediction using a genetic algorithm. International Journal of Automotive and Mechanical Engineering. 2015;11:257181.

[24] Shelton SM, Swanger WH. Fatigue properties of steel wires. Journal of Research of the National Bureau of Standards. 1935;14:17-32.

[25] Verpoest I, Aernoudt E, Deruyttere A, De Bondt M. The fatigue threshold, surface condition and fatigue limit of steel wire. International journal of fatigue. 1985;7:199-214.

[26] Beretta S, Boniardi M. Fatigue strength and surface quality of eutectoid steel wires. International Journal of Fatigue. 1999;21:329-35.

[27] Cruzado A, Leen S, Urchegui M, Gómez X. Finite element simulation of fretting wear and fatigue in thin steel wires. International Journal of Fatigue. 2013;55:721.

[28] Siswanto WA, Nagentrau M, Tobi M, Latif A. Prediction of residual stress using explicit finite element method. Journal of Mechanical Engineering and Sciences. 2015;9:1556-70.

[29] Toribio J, Ovejero E. Effect of cumulative cold drawing on the pearlite interlamellar spacing in eutectoid steel. Scripta Materialia. 1998;39:323-8.

[30] Toribio J, González B, Matos J. Fatigue and fracture paths in cold drawn pearlitic steel. Engineering Fracture Mechanics. 2010;77:2024-32.

[31] Shaari MS, Akramin MRM, Ariffin AK, Abdullah S, Kikuchi M. Prediction of fatigue crack growth for semi-elliptical surface cracks using S-version fem under tension loading. Journal of Mechanical Engineering and Sciences. 2016;10:237586.

[32] Beretta S, Matteazzi S. Short crack propagation in eutectoid steel wires. International Journal of Fatigue. 1996;18:451-6.

[33] Lambrighs K, Wevers M, Verlinden B, Verpoest I. A fracture mechanics approach to fatigue of heavily drawn steel wires. Procedia Engineering. 2011;10:3259-66.

[34] Kachanov LM. Rupture time under creep conditions. Izv AN SSSR, Otd Tekhn Nauk. 1958;8:26-31.

[35] Imrak CE, Erdönmez C. On the problem of wire rope model generation with axial loading. Mathematical and Computational Applications. 2010;15:259-68.

[36] Johnson GR, Cook WH. Fracture characteristics of three metals subjected to various strains, strain rates, temperatures and pressures. Engineering Fracture Mechanics. 1985;21:31-48.

[37] Rice JR, Tracey DM. On the ductile enlargement of voids in triaxial stress fields*. Journal of the Mechanics and Physics of Solids. 1969;17:201-17.

[38] Lemaitre J. A continuous damage mechanics model for ductile fracture. Transactions of the ASME Journal of Engineering Materials and Technology. 1985;107:83-9.

[39] Lemaitre J. A course on damage mechanics: Springer Berlin Heidelberg; 1996. 